\title{
Structure and Properties of Sn-9Zn Lead-Free Solder Alloy with Heat Treatment
}

\author{
Mahmoud Hammam ${ }^{1}$, Fardos Saad Allah ${ }^{2}$, El Said Gouda ${ }^{2,3}$, Yaser El Gendy ${ }^{1}$, Heba Abdel Aziz ${ }^{1}$ \\ ${ }^{1}$ Physics Department, Helwan University, Helwan, Egypt \\ ${ }^{2}$ Metal Physics Lab., Department of Solid State Physics, National Research Center, Dokki, Egypt \\ ${ }^{3}$ Physics department, Jazan University, Jazan, KSA \\ Email: gouda.el73@yahoo.com
}

Received November 20, 2009; revised December 17, 2009; accepted December 22, 2009

\begin{abstract}
The Sn-9Zn lead-free solder alloy was prepared by conventional casting technique then cold-rolled into long sheets of $1 \mathrm{~mm}$ thickness and $3 \mathrm{~mm}$ width. It was annealed at 80,120 and $160^{\circ} \mathrm{C}$ for 60 min to investigate the effect of isochronal heat treatment on structure and mechanical properties of the cold rolled Sn-9Zn alloy. The results showed that, the crystallite size and lattice strain have opposite behavior with increasing annealing temperature due to recovery and recrystalization processes associated with the heat treatment process. Vickers micro-hardness number increases continuously from 155 to $180 \mathrm{MPa}$ with increasing annealing temperature. Ultimate tensile strength (UTS) was also calculated. It was found that, it is equal to $61.4 \mathrm{MPa}$ for the non annealed sample and slightly decreases to 60.5 and $58.2 \mathrm{MPa}$ for samples annealed at 80 and $120^{\circ} \mathrm{C}$, respectively. While, increases to $65.4 \mathrm{MPa}$ for the sample annealed at $160^{\circ} \mathrm{C}$. Also, ductility increases with increasing annealing temperature in opposite manor with the UTS. The new method for Micro-creep behavior as well as the creep rate calculated by this method has been characterized at room temperature.
\end{abstract}

Keywords: Cold Rolling, Annealing, Lead-Free Solder Alloy, Micro-Creep, Micro-Hardness

\section{Introduction}

There are some characteristics which play a major role in the consideration of substitutes for tin-lead solders in electronic soldering, such as a lower melting temperature of solder, adequate strength, the environmental issues related to the toxicity, good electrical/thermal conductivity, low cost, good wetting properties, and availability in sufficient quantities as concerns the base metal. These properties are mostly affected by the methods of preparation of the alloys such as rapid solidification, conventional casting or unidirectional solidification. Furthermore, the working process of the alloys, isochronal, isothermal heat treatments and aging time all of these parameters are mostly affect on the properties of these alloys [1-3]. The present paper concerns with the effect of isochronal heat treatment on structure and properties of Sn-9Zn cold rolling alloy. This alloy is one of the most alloys recommended being alternative to $\mathrm{Pb}-\mathrm{Sn}$ alloy [4-7]. This recommendation is due to its lower melting point close to that of $\mathrm{Sn}-\mathrm{Pb}\left(183^{\circ} \mathrm{C}\right)$ eutectic alloy and its mechanical properties, e.g. tensile strength is better than that of the $\mathrm{Sn}-\mathrm{Pb}$ alloy [8]. Moreover, $\mathrm{Sn}-\mathrm{Zn}$ alloy is advantageous from the economic point of view because $\mathrm{Zn}$ is a low cost metal.

\section{Experimental}

The materials in the alloy of composition Sn-9Zn of purities of $99.98 \%$ were weighted out and melted in a porcelain crucible using an electrical furnace with calevony as a fluxing agent. The casting was done in a graphite mold at a temperature of $500^{\circ} \mathrm{C}$ and thermally agitated to perform the homogenization. The resulting alloy was cold rolling into long sheets of about $3 \mathrm{~mm}$ in width and $1 \mathrm{~mm}$ in thickness. The alloy samples as illustrated in Table 1 were isochronal heat treated at 80,120 and $160^{\circ} \mathrm{C}$ for 60 min to perform the effect of heating temperature on structure and properties of these samples. X-ray diffraction analysis was performed using a 1390 Philips Diffractometer with $\mathrm{Cu}-\mathrm{K}_{\alpha}$ radiation $(\lambda=1.54056 \mathrm{~A})$ to determine the phases present. Differential thermal analysis test (DTA) during heating with heating rate of $10^{\circ} \mathrm{C} / \mathrm{min}$ was used to identify the melting reaction of these samples. The polished samples were tested in a Vickers microhardness tester, where a diamond pyramid indenter 
with square base is used and the Vickers hardness number is given by $\mathrm{HV}=0.185 \mathrm{~F} / \mathrm{d}^{2}$, where $\mathrm{F}$ is the applied load in $\mathrm{N}$ and $\mathrm{d}$, is the average diagonal length in $\mathrm{mm}$. Each reading was an average of at least ten separate measurements taken at random places on the surface of the specimens. All of the indentations were at least 0.5 $\mathrm{mm}$ away from the edges and from other indentations. Micro-creep measurements [2,9] were carried out on all samples using a fixed load $0.49 \mathrm{~N}$ for dwell time up to $300 \mathrm{~s}$. Tensile properties were determined using a con- ventional testing machine with fixed cross head speed at $10 \mathrm{~mm} / \mathrm{min}$.

\section{Results and Discussion}

\subsection{Structure of Sn-Zn Alloy Samples}

Figure 1 shows the profiles of XRD patterns of the Sn9Zn cold rolled alloy samples before and after isochronal

Table 1. Chemical analysis of the Sn-9Zn alloy before and after annealing.

\begin{tabular}{cccccc}
\hline Sample & Chemical formula & $\mathrm{Zn}$ & $\mathrm{Pb}$ & $\mathrm{Sn}$ & Annealing temperature ${ }^{\circ} \mathrm{C}$ \\
\hline Sample 1 & $\mathrm{Sn-9Zn}$ & 9.02 & 0.04 & $\mathrm{Bal}$ & Pre-annealed \\
Sample 2 & $\mathrm{Sn}-9 \mathrm{Zn}$ & 9.02 & 0.04 & $\mathrm{Bal}$ & 80 \\
Sample 3 & $\mathrm{Sn}-9 \mathrm{Zn}$ & 9.02 & 0.04 & $\mathrm{Bal}$ & 120 \\
Sample 4 & $\mathrm{Sn}-9 \mathrm{Zn}$ & 9.02 & 0.04 & $\mathrm{Bal}$ & 160 \\
\hline
\end{tabular}
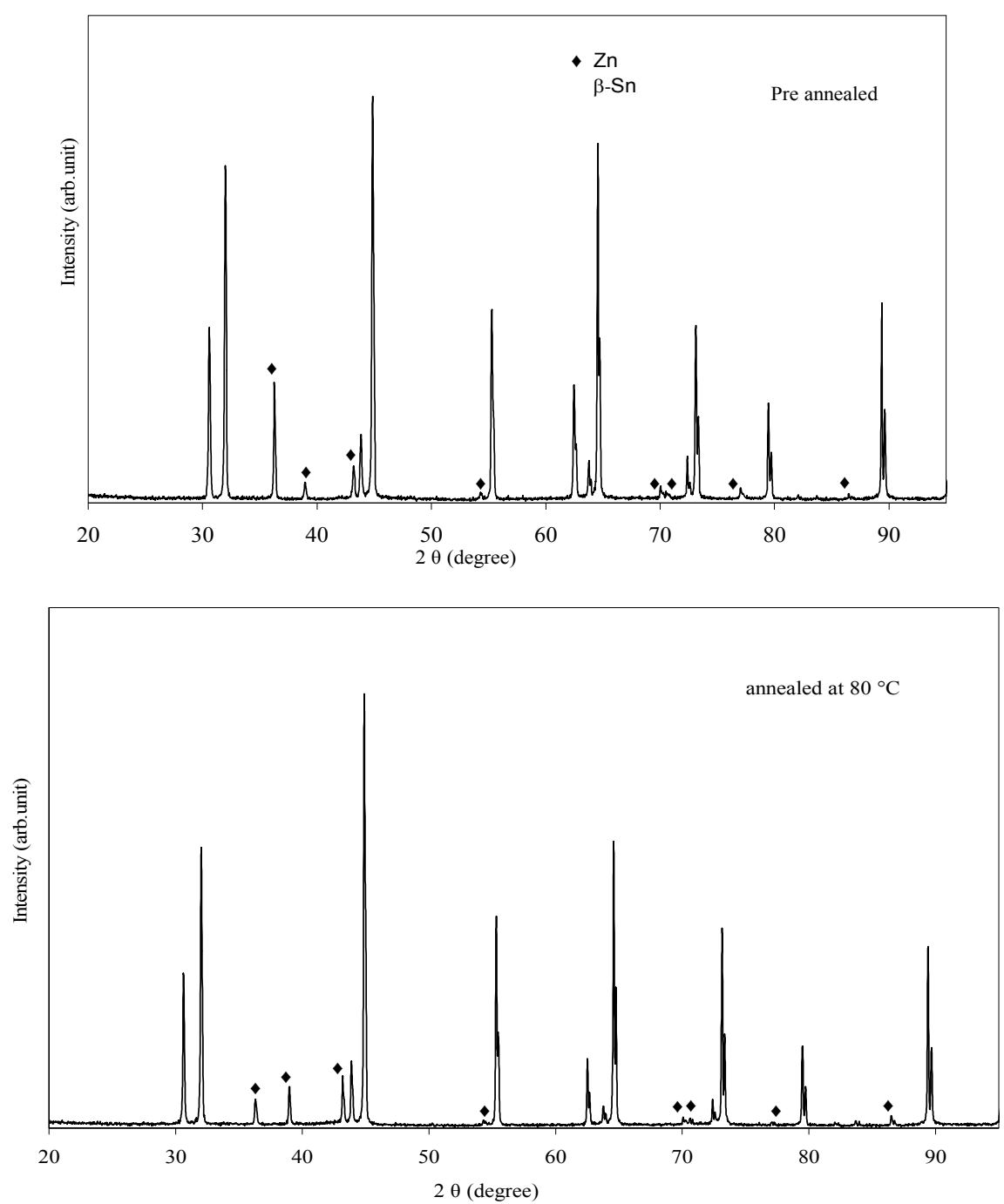

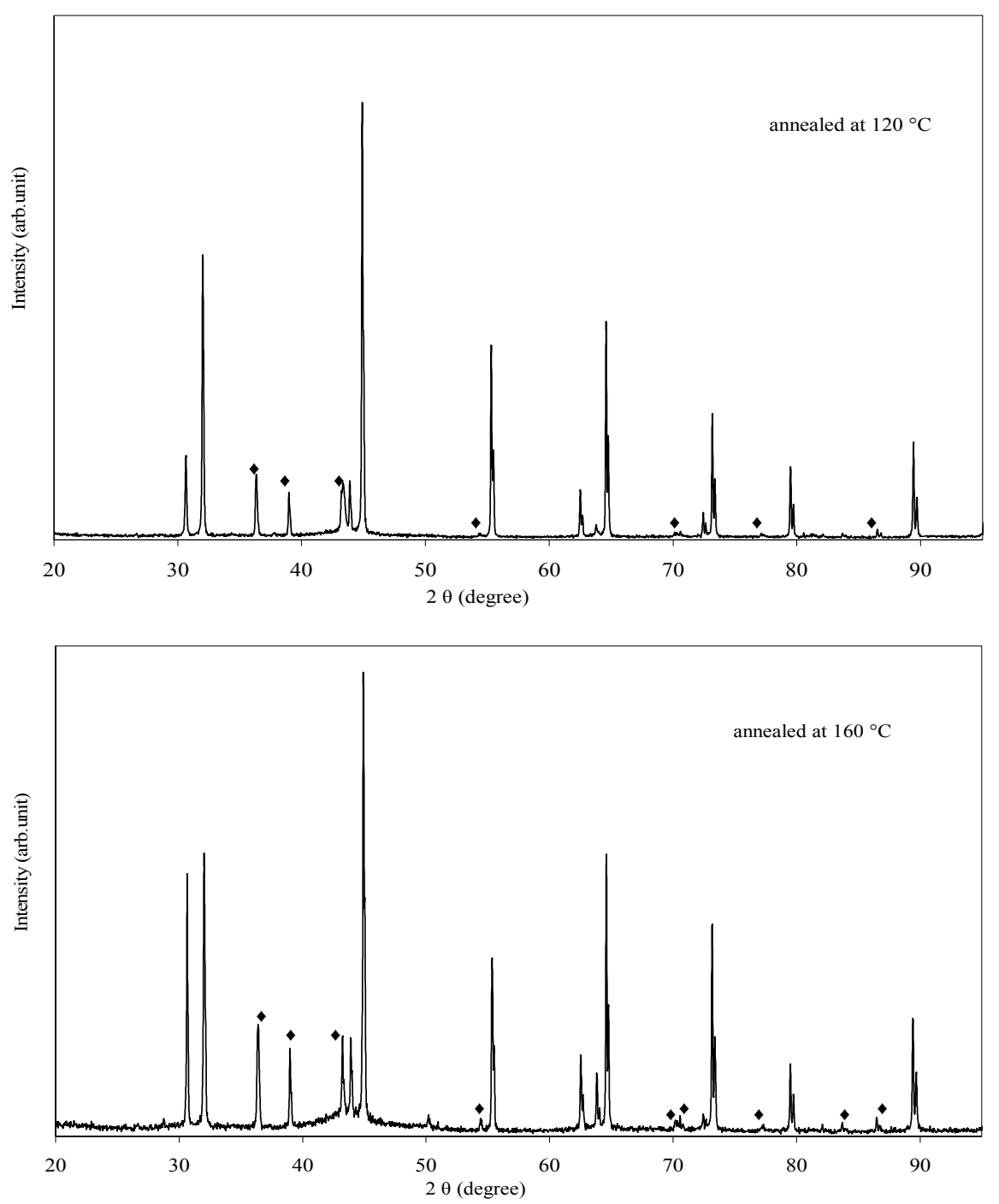

Figure 1. XRD patterns of Sn-9Zn alloy samples before and after annealing.

heat treatment at 80,120 , and $160^{\circ} \mathrm{C}$ for $60 \mathrm{~min}$. Each of the alloy samples exhibit the X-ray diffraction peaks due to $\beta$-Sn matrix phase with some precipitations of $\mathrm{Zn}$ as a secondary phase. The effect of the isochronal heat treatment is restricted only on the lattice strain and crystallite size [10] of the Sn-matrix phase as illustrated in Figure 2. The crystallite size of Sn-matrix is continuously increaseed, while the lattice strain has an opposite behavior with increasing the annealing temperature as shown in Figure 2. Actually, cold rolling process may cause an increase in dislocation density then caused the lattice to be strained. Such an array of dislocations gives rise to a substantial strain energy stored in the lattice, so it becomes unstable thermodynamically relative to the undeformed one. Consequently, the deformed alloy will try to return to a state of lower free energy, i.e. a more perfect state through the continuous heat treatment process where thermally activated processes such as diffusion, cross slip and climb take place.

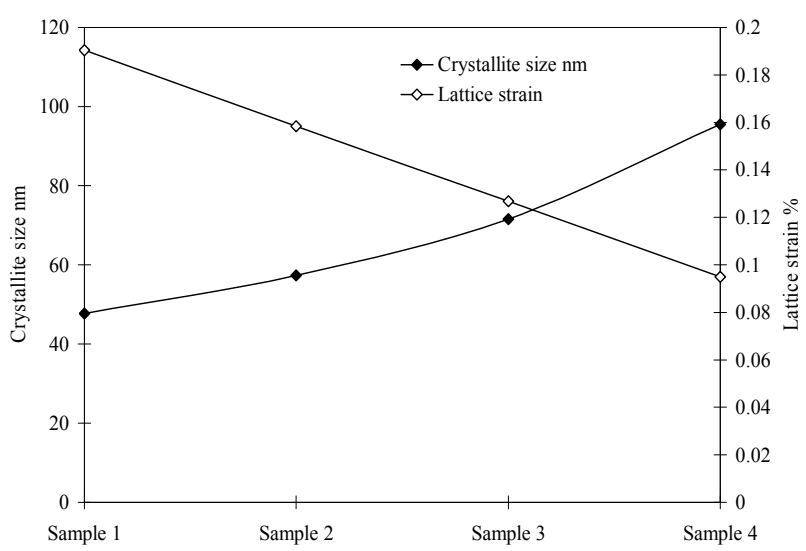

Figure 2. Crystallite size and lattice strain of Sn-9Zn samples before and after annealing. 


\subsection{Thermal Properties of Sn-Zn Alloy Samples}

Figure 3 shows the typical DTA profiles of Sn-9Zn alloy samples before and after annealing at 80,120 and $160^{\circ} \mathrm{C}$ for $60 \mathrm{~min}$ during heating with heating rate $10^{\circ} \mathrm{C} / \mathrm{min}$. A large endothermic peak corresponding to the melting reaction was observed for each sample and seems to have the same physical origin. There is no any phase transition occur other than the melting. The melting point of each sample was determined as illustrated in Table 2. It shows a slight decrease of the melting point in a narrow range of temperatures $\left(199.9\right.$ to $\left.198.7^{\circ} \mathrm{C}\right)$. Also, the heat of fusion, $\Delta H$, can be determined by $H=K A / m$, [11] where $K$, is a constant which is defined as a calibration coefficient that depends on the crucible shape and regards as a constant in the DTA system, $m$ is the mass of the sample, and $A$ is the area under the endothermic peak. A slight change of heat of fusion in the range of 82.9 to 87 was observed as illustrated in Table 2, which are lower values compared with that of $\mathrm{Pb}-\mathrm{Sn}$ (104.2) [12]. This means, the Sn-Zn alloy is considered as the most beneficial material for saving energy.

\subsection{Tensile Measurements}

Figure 4 shows the stress-strain curve of Sn-9Zn alloy samples before and after heat treatment. It shows an increase in the strain as the stress is increased by different amounts. The stress-strain curves can be divided into two regions; the first region which is a linear relation between stress and strain ends at the strain ratio $\sim 0.1$ of the second region. The second region is slightly curved due to the yielding. Also, it is noticed that the annealed samples have higher values than that of the non-annealed sample. It is also seen from Figure 4 that, after the peak tensile stresses at 0.1 strains, the alloy samples have a

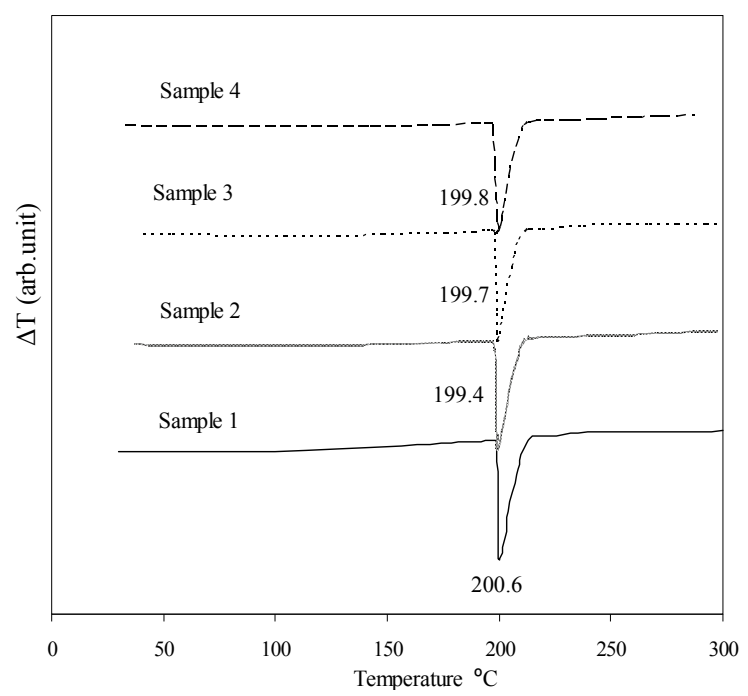

Figure 3. DTA endothermic peak of Sn-9Zn alloy samples.

Table 2. Melting properties of Sn-9Zn samples before and after annealing.

\begin{tabular}{cccccc}
\hline Sample & Melting point & ${ }^{\circ} \mathrm{C}$ & Onset ${ }^{\circ} \mathrm{C}$ & Offset ${ }^{\circ} \mathrm{C}$ & $\Delta \mathrm{H} \quad(\mathrm{J} / \mathrm{g})$ \\
\hline Sample 1 & 199.9 & 193.8 & 212.7 & 82.9 \\
Sample 2 & 198.7 & 187.5 & 211 & 84.2 \\
Sample 3 & 198.9 & 188.9 & 211.2 & 87 \\
Sample 4 & 199.1 & 190.1 & 211.8 & 86.6 \\
\hline
\end{tabular}

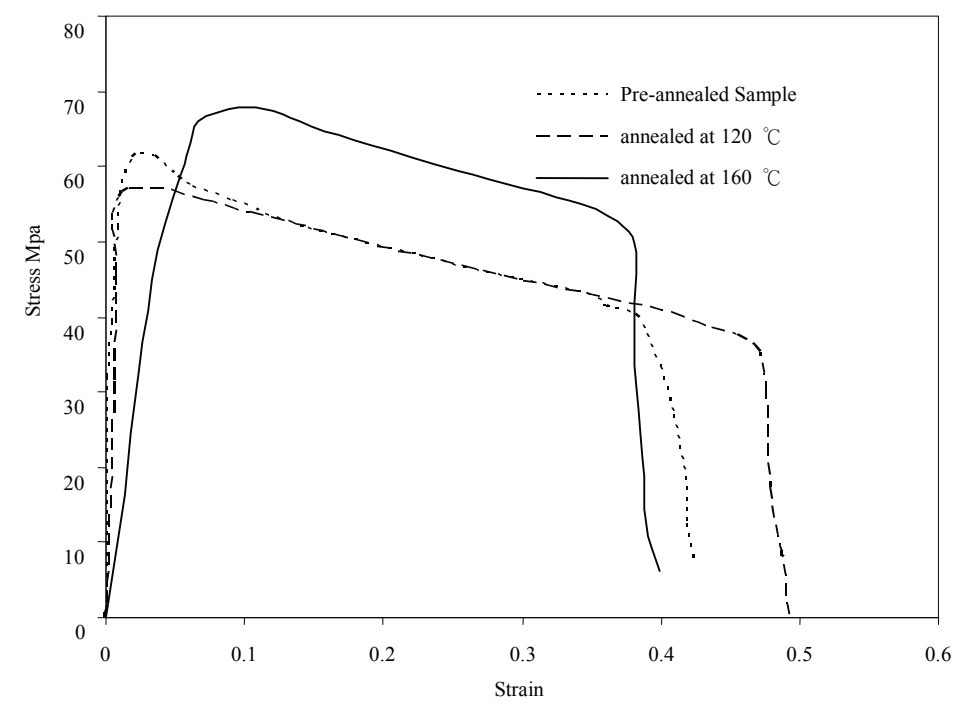

Figure 4. Stress-strain curve of the Sn-9Zn alloy samples. 
neck. Also, it indicates the deformation up to failure is distributed much more uniformly throughout the alloy volume. The ultimate tensile strength, UTS, which is the maximum engineering stress that a material can withstand in tension, was calculated as illustrated in Figure 5. It is equal to $61.4 \mathrm{MPa}$ for sample 1 , which slightly decreases to 60.5 and $58.2 \mathrm{MPa}$ for samples 2 and 3, respectively. While, the value increases to its maximum value $65.4 \mathrm{MPa}$ for sample 4 .

\subsection{Micro Hardness Measurement}

Micro-hardness measurement is a very sensitive to detect the structural changes of different soft solders. Usually, it is a non-destructive testing and can be the easiest way to determine the mechanical properties of the different phases of the structure. Figure 6 shows the variation of Vickers hardness number of Sn-9Zn alloy samples before and after heat treatment using loads of $0.098,0.245$ and

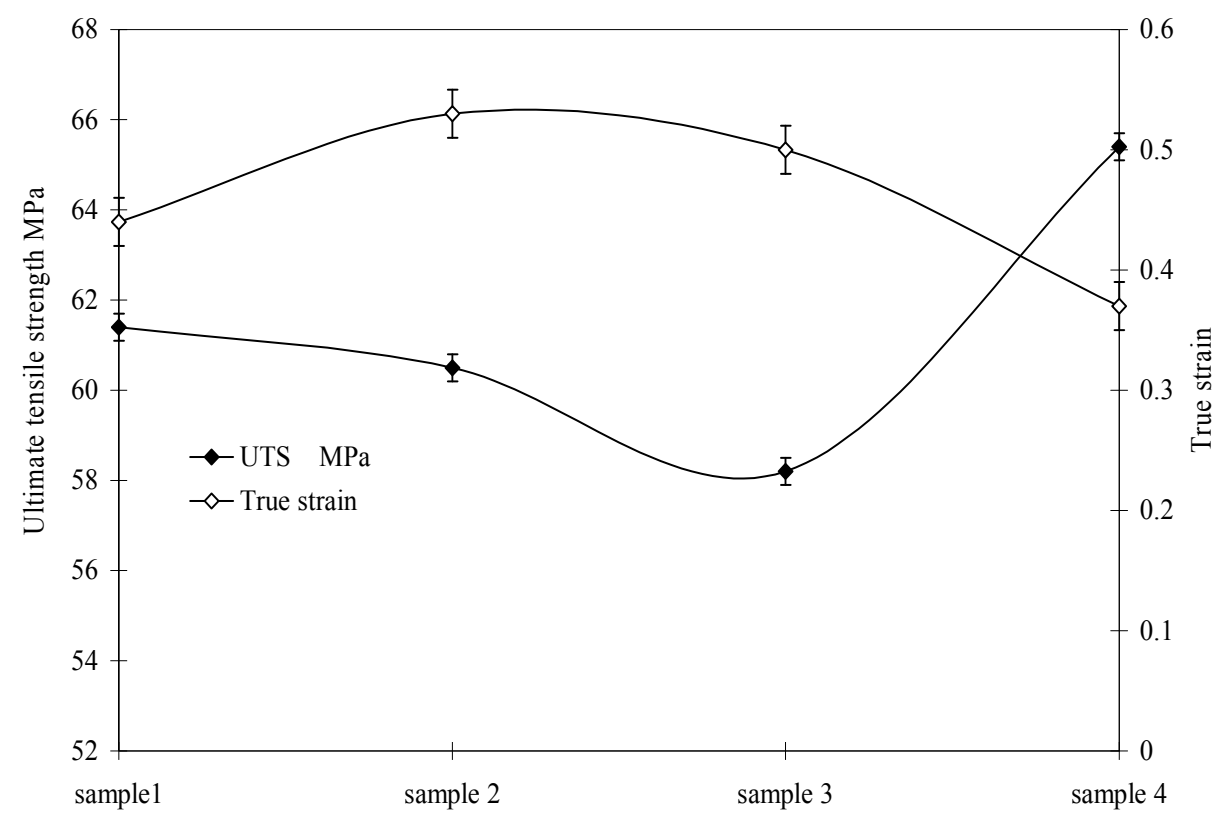

Figure 5. UTS and true strain of Sn-9Zn samples before and after annealing.

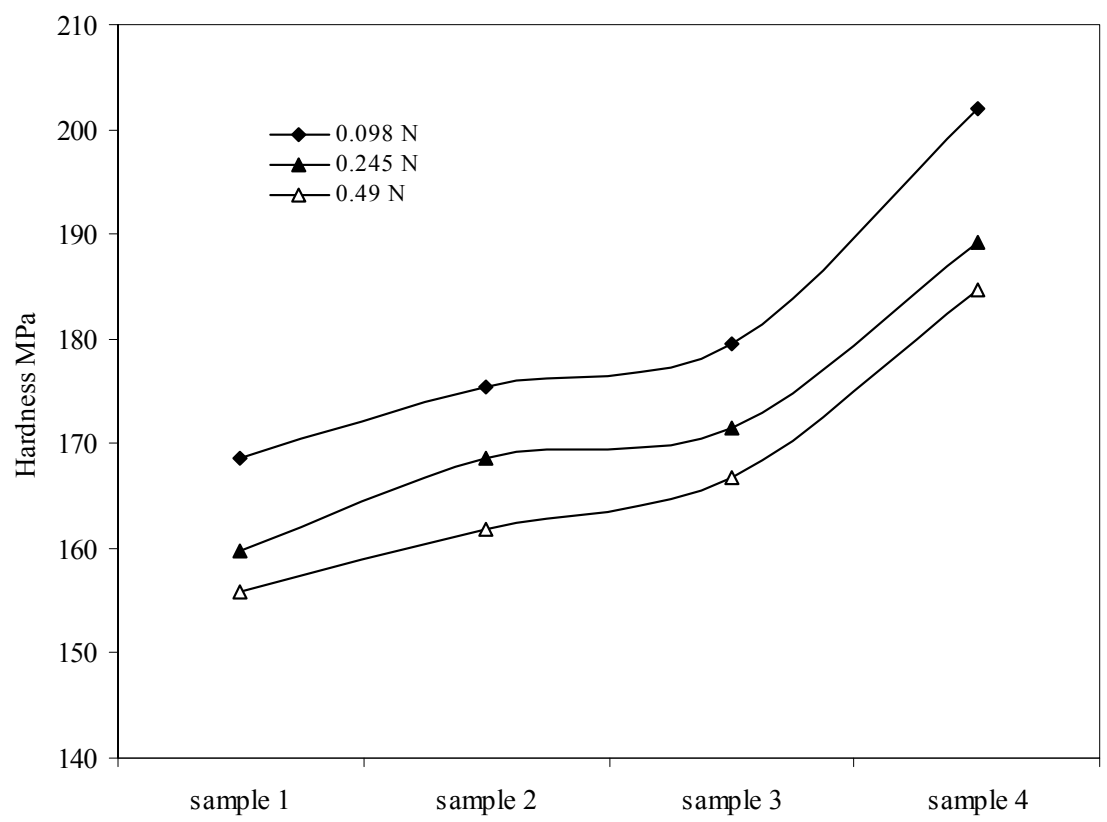

Figure 6. Hardness values of Sn-9Zn samples before and after annealing. 
$0.49 \mathrm{~N}$ for fixed dwell time of $10 \mathrm{~s}$. The hardness increases continuously as the annealing temperature is increased for the three load systems by the same manor. This increase can be attributed to the effect of heat treatment that decreases the lattice strain induced through the cold rolling process. The hardening in metals and alloys induced by forming structure in which dislocation mobility is reduced due to the interaction of dislocations with impurity atoms and the formation of second phase particles. Also, reduction of the lattice strain leads to increase the hardness. Another point is noticed from this figure that the values of $\mathrm{HV}$ in all samples are decreased with increasing applied load, which well known as indentation size effect and agree with the results observed elsewhere $[13,14]$.

\subsection{Micro-Creep Behavior}

Figure 7 shows the variation of local strain with indentation time through the interval 0 to $300 \mathrm{~s}$. All of the alloy samples have two stages namely as primary and secondary creep. The first stage starts from the beginning to $120 \mathrm{~s}$, followed by the second stage up to $300 \mathrm{~s}$. This

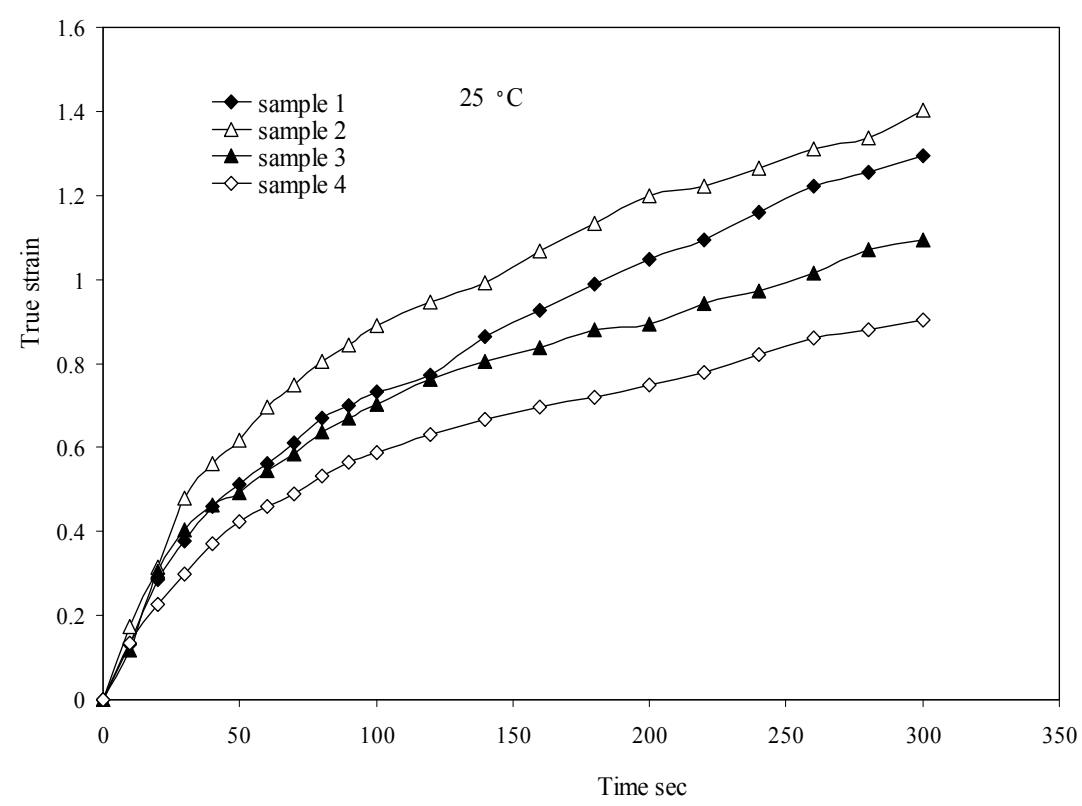

Figure 7. Micro-creep curve of Sn-9Zn samples before and after annealing.

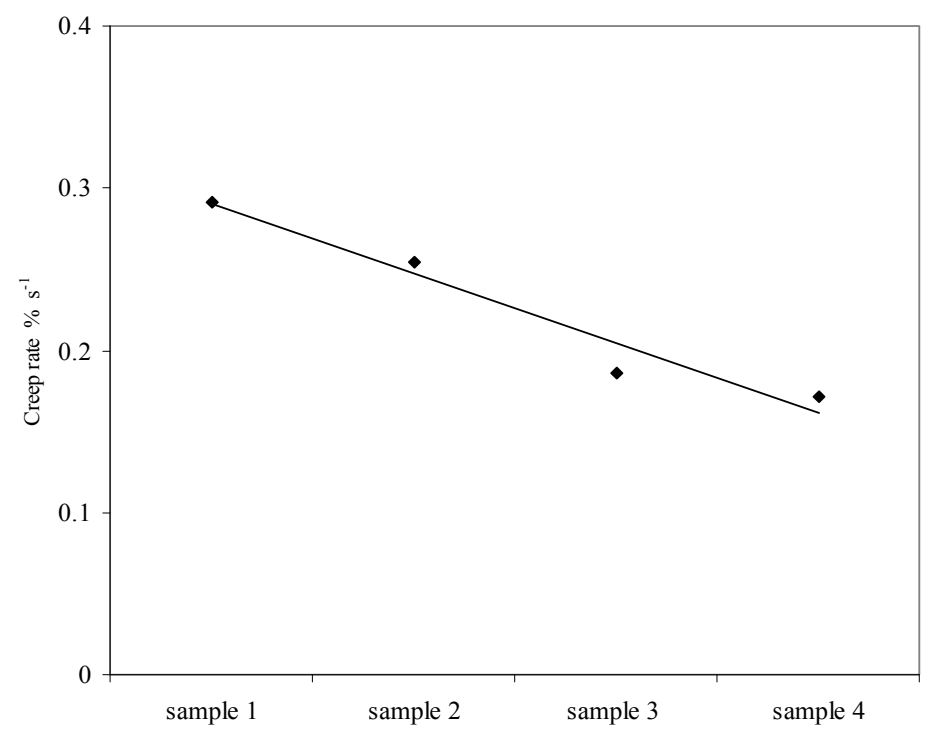

Figure 8. Creep rate of $\mathrm{Sn-9Zn}$ alloy samples. 
stage called the steady state region in which the strain increases linearly with indentation time. The third stage of creep is not noticed here since it is impossible because this method is a compressed method. From the steady state region, the creep rate of the alloy samples can be calculated and the results are illustrated in Figure 8. It shows a continues decrease of creep rate with increasing annealing temperature which indicates that, the annealed samples have higher creep resistance due to the decrease of the lattice strain as illustrated from the X-ray diffraction analysis.

\section{Conclusions}

The present paper aimed to study the effect of annealing temperature i.e. 80,120 and $160^{\circ} \mathrm{C}$ for $60 \mathrm{~min}$ on structure and mechanical properties of $\mathrm{Sn}-9 \mathrm{Zn}$ alloy prepared by conventional casting technique then subjected to cold-rolling process. The results showed that:

1) The crystallite size of Sn-matrix phase was increased continuously with increasing annealing temperature, while the lattice strain induced through the cold rolling process was decreased.

2) Vickers hardness number of this alloy increased continuously with increasing annealing temperature. Also, the hardness values were decreased with increasing applied load, which agree with other previous works.

3) The micro-creep behavior of this alloy was also described, which differ than that obtained by tensile methods by the third stage of creep. So, the micro-creep method is not destructive method and useful for small samples of alloys.

4) The creep rate calculated by this method was decreased continuously with increasing annealing temperature.

\section{References}

[1] M. Kamal and E. S. Gouda, "Effect of rapid solidification on structure and properties of some lead-free solder alloy," Materials and Manufacturing Processes, Vol. 21, pp. 736-740, 2006.

[2] E. S. Gouda, E. Ahmed and F. Saad Allah, "Electrical and mechanical properties of Sn-5wt.\%Sb alloy with annealing temperature," European Physical Journal: Ap- plied Physics, Vol. 45, pp. 10901-10905, 2009.

[3] E. S. Gouda, "Effect of cooling rate on structure and creep behavior of Sn-0.7 Cu-0.5 Zn lead-free solder alloy," European Physical Journal: Applied Physics, Vol. 48, pp. 20902-20906, 2009.

[4] R. Islam, B. Wu, M. Alam, Y. Chan and W. Jillek, "Investigations on microhardness of $\mathrm{Sn}-\mathrm{Zn}$ based lead-free solder alloys as replacement of Sn-Pb solder," Alloys and Compounds, Vol. 392, pp. 149-158, 2005.

[5] M. Kamal, M. Meikhail, A. Elbediwi and E. S. Gouda, "Study of structural changes and properties of Sn-9Zn lead free solder alloy with addition of different alloying elements," Radiation Effects and Defects in Solids, Vol 160, pp. 45-49, 2005.

[6] J. Zhao, L. Qi, X. Wang and L. Wang, "Influence of Bi on microstructures evolution and mechanical properties in Sn-Ag-Cu lead-free solder," Alloys and Compounds, Vol. 375, pp. 196, 2004.

[7] M. Kamal and E. S. Gouda, "Enhancement of solder properties of Sn-9Zn lead-free solder alloy," Crystal Research and Technology, Vol. 41, No. 12, pp. 1210-1213, 2006

[8] C. M. Wu, D. Q. Yu, C. M. T. Law and L. Wang, “ The properties of Sn-9Zn lead-free solder alloys doped with trace rare earth elements," Electronic Materials, Vol. 31, pp. 921-927, 2002.

[9] T. El-Ashram and R. Shalaby, "Effect of rapid solidification and small additions of $\mathrm{Zn}$ and $\mathrm{Bi}$ on structure and properties of $\mathrm{Sn}-\mathrm{Cu}$ eutectic alloy," Electronic Materials, Vol. 34, pp. 212-215, 2005.

[10] B. E. Warren, "X-Ray diffraction," Addison Wesley, Reading, MA, 1969.

[11] M. Brown, "Introduction to thermal analysis," Wiley, New York, pp. 33-35, 1986.

[12] W. Wendlandt, "Thermal analysis," Wiley, New York, pp. 271-274, 1986.

[13] O. Uzuna, T. Karaaslan, M. Gogebakan and M. Keskin, "Hardness and microstructural characteristics of rapidly solidified Al-8-16 wt.\%Si alloys," Alloys and Compounds, Vol. 376, pp. 149, 2004.

[14] M. Kamal, E. S. Gouda and L. Marei, "Effect of Bi addition on hardness and micro creep behavior of $\mathrm{Sn}-3.5 \mathrm{Ag}$ rapidly solidified alloy," Crystal Research and Technology, Vol. 44, No. 12, pp. 1308-1812, 2009. 